\title{
Variability of eye colour mutations in natural populations of Drosophila melanogaster
}

\author{
Carmen NÁJERA and J.L. MÉNSUA \\ Facultad de Ciencias Biológicas, Universidad de Valencia, Departamento de Genética, \\ $D^{r}$ Moliner, 50, Burjasot, Valencia, Spain
}

\begin{abstract}
Summary
In order to compare the variability of eye colour mutations in natural populations, of $D$. melanogaster, six captures were carried out in three different habitats (cellar, vineyard and pinewood) and at two different seasons of the year (spring and autumn). Inbreeding by $F_{1}$ pair mating of isolated wild females was used, and eight pairs of this $F_{1}$ generation were crossed. The total number of heterozygous loci was 87 , the average proportion of heterozygous females 40.68 and the average number of mutations per female 0.47 , the total number of mutations per fly being significantly higher in the cellar habitat. There were no significant differences between the seasons. The effective sizes estimated were high in all cases (cellar : 12000 ; vineyard : 15000 and pinewood : 17500 ) and the average heterozygosity low (0.11).
\end{abstract}

Key words : D. melanogaster, natural population, genetic variability, eye colour mutation.

\section{Résumé}

Variabilité des mutations de la couleur des yeux dans des populations naturelles de Drosophila melanogaster

Le polymorphisme de la couleur des yeux a été étudié dans des populations naturelles de D. melanogaster à partir de six échantillons capturés, au printemps et à l'automne, dans trois habitats différents (cave, vignoble et pinède). La recherche des mutations récessives a été effectuée en croisant, pour chaque femelle sauvage isolée, huit couples de ses descendants appartenant à la génération $F_{1}$. Le nombre total de locus en hétérozygotie est de 87 , la proportion moyenne de femelles hétérozygotes 40,68 et le nombre moyen de mutations par femelle 0,47 . Le nombre de mutations par mouche est significativement plus élevé dans les populations de cave, mais ne varie pas avec les saisons. L'effectif génétique des populations analysées est élevé (cave : 12000 ; vignoble : 15000 ; pinède : 17500$)$, alors que leur hétérozygotie moyenne est faible $(0,11)$. yeux.

Mots clés : D.melanogaster, population naturelle, variabilité génétique, mutant de la couleur des

\section{Introduction}

The evolutionary process is conditioned by the existence of genetic variability. The description of this genetic variability in a population is the first step in studies of 
evolution and it is necessary to explain its origin and its maintenance and to predict its evolutionary consequences. In wild populations a great deal of genetic variability exists. The greater part of this variability is hidden and can be detected by simple experimental methods including the search for visible mutations.

From Chetverikov (1926, quoted by SPENCER, 1947) - who was the first investigator to study the extent of genetic variability in wild Drosophila populations - to BcEsIGER (1953), various studies indicate that populations contain a large amount of hidden genetic variability. These populations differ however in their mutant gene contents and in their structure under different geographical and environmental conditions (Hedrick et al., 1976 ; Singh et al., 1982 ; InOUe et al., 1984 ; KuSAKabe \& MukaI, $1984 a$ and $b$ ).

In a previous work (NÁJERA \& MÉNSUA, 1985a) analyzing variability in a cellar population of D.melanogaster, the number of eye colour mutations carried in heterozygous females was very high. In order to compare this variability in different natural populations, a study of eye colour mutations was made in different populations with respect to habitat and time of capture.

\section{Material and methods}

Six collections of adults of D.melanogaster were made in three different geographic areas : two of the captures were carried out inside a cellar in Requena (Valencia, Spain), two in a vineyard in El Pontón ( $4 \mathrm{~km}$ away from the cellar) and the last two in a semi-built-up pine-wood at La Cañada (70 km away from Requena). In order to study the cellar and vineyard populations before and after vintage, the flies were captured in spring and autumn. Because species other than D.melanogaster were present in the collections, we have identified males of D.melanogaster by their genitalia (Sturtevant, 1919) and females by the genital aspect of their male progeny.

The females analyzed from each of the six populations (the number of which varied between 45 and 80 ) were isolated individually in food vials to obtain the $F_{1}$, in which dominant or sex-linked mutations can be detected visually. To detect recessive mutants, we have used SPENCER's method (1947). For each wild female, eight pairs of its $F_{1}$ were crossed to obtain the $F_{2} ; 70$ individuals of each $F_{2}$ were observed to detect homozygous individuals bearing recessive mutations, both for the colour and morphology of the eyes. In cases of doubtful phenotype in the $F_{2}$, or when the number of individuals considered mutants were not in Mendelian proportions, the $F_{3}$ and later generations were observed.

The mutants found in each population were isolated to originate laboratory strains. These strains were kept on the usual medium (corn-yeast) supplemented with live yeast and maintained at $19 \pm 1{ }^{\circ} \mathrm{C}$ in a thermoregulated chamber with a daily light-darkness cycle of respectively 16 and 8 hours.

Allelism tests were carried out within each of the six populations studied and between populations, comparing each one with the remaining five. In order to reduce the total number of crosses, the flies were crossed according to three eye phenotypes : dark colour $(D E)$, light colour $(L E)$ and caramel $(C E)$. Thus, three types of crosses 
were defined : $D E \times D E, L E \times L E$ and $C E \times C E$. This procedure was followed on the assumption that dark and light eyes are due to mutations which block different metabolic pathways and that caramel eyes are due to mutations which affect both pathways at the same time or affect the deposition of the pigment granules. When the offspring from these crosses had a phenotype similar to the parents, the two mutations are considered to be controlled by the same locus. The allelism experiments were carried out at a temperature of $25 \pm 1{ }^{\circ} \mathrm{C}$ in a thermoregulated chamber with permanent light, and humidity varying between 60 and $65 \%$.

The statistical methods were : the factorial ANOVA using the arc-sine transformation for percentages, a studenT-NEWMAN-KEULS multiple range test (SoKAL \& RohlF, 1981) and a factorial analysis of correspondences (LEgENDRE \& LEgENDRE, 1979).

The effective sizes of these populations were estimated by the « temporal method » of Krimbas \& TSAKas (1971), applying the estimator of PollaK (1983), the increase of the allelic frequency at each locus being the difference between the values found in the spring and autumn collections and considering the generations passed between the two collections. The average heterozygosity was calculated, following the methods of Lewontin \& Hubby (1966) and Nei (1978). Finally, the genetic distances between the six populations were estimated using five different indexes (SoKal \& SNEATH, 1963 ; Cavalli-Sforza \& Edwards, 1967 ; NeI, 1972 ; Rogers, 1972 ; Prevosti, 1974).

\section{Results}

In the two collections made inside the cellar, there is a large disproportion between the number of individuals collected before and after vintage (in spring 89 females and 74 males and in autumn 350 females and 187 males) although the duration of the two collections was similar. There is also an excess of females in the autumn collection $\left(\chi^{2}=48.80, P<0.01\right)$ while in spring no significant difference $\left(\chi^{2}=1.2, \mathrm{~ns}\right)$ is visible. In the vineyard and in the pine-wood collections, there is an excess of males in autumn (respectively 154/56 and 61/51), while in spring there is an excess of females (respectively $49 / 78$ and $68 / 72$ ). By means of a homogeneity $\chi^{2}$, it can be verified that there is no homogeneity either as regards the habitats $\left(\chi^{2}=47.67, P<0.01\right)$ or the seasons $\left(\chi^{2}=22.34, P<0.01\right)$.

A sepia male was found inside the cellar in the autumn collection. In the $F_{1}$, no dominant eye colour mutation was detected, but sex-linked mutations were detected in five of the six collections.

Table 1 gives the percentage of heterozygous females and the number of mutations per fly for eye colour and eye morphology in the six populations analyzed. By means of a two way ANOVA, significant differences between the habitats can be observed for the number of mutations per fly $\left(\mathrm{F}_{2.2}=21.42, \mathrm{P}<0.05\right)$, but not between the seasons $\left(F_{1,2}=2.00, n s\right)$. The sTUDENT-NEWMAN-KEULS multiple range test groups the vineyard and the pine-wood populations but not the cellar one which has a higher mean. For the total number of eye morphology mutations per fly there were no significant differences, either among the three habitats or between the two seasons of the year.

The frequencies of eye colour mutants found in these populations ranged from $3.12 \times 10^{-2}$ to $0.31 \times 10^{-2}$. The populations with the lowest frequencies are logically 


\section{TABLE 1}

Percentage of heterozygous females and number of eye colour and eye morphology mutations per female in natural populations of D.melanogaster

\begin{tabular}{|c|c|c|c|c|}
\hline \multirow{2}{*}{ Populations } & \multicolumn{2}{|c|}{ Eye colour } & \multicolumn{2}{|c|}{ Eye morphology } \\
\hline & Heteroz. females & Mutations & Heteroz. females & Mutations \\
\hline$\underset{(68)}{\text { Cellar autumn }} \ldots \ldots$ & 52.94 & 0.62 & 8.82 & 0.09 \\
\hline Cellar spring $\ldots \ldots$ & 52.50 & 0.65 & 8.75 & 0.09 \\
\hline $\begin{array}{c}\text { Vineyard autumn } \\
(51)\end{array}$ & 25.49 & 0.25 & 5.88 & 0.06 \\
\hline$\underset{(70)}{\text { Vineyard spring } \ldots}$ & 32.85 & 0.39 & 4.29 & 0.04 \\
\hline $\begin{array}{l}\text { Pine-wood autumn } \\
\qquad(45)\end{array}$ & 37.77 & 0.40 & 2.22 & 0.02 \\
\hline $\begin{array}{c}\text { Pine-wood spring } \\
(67)\end{array}$ & 35.82 & 0.40 & 5.97 & 0.06 \\
\hline Total cellar & 52.70 & 0.63 & 8.78 & 0.09 \\
\hline Total vineyard . & 29.75 & 0.33 & 4.96 & 0.05 \\
\hline Total pine-wood & 36.61 & 0.40 & 4.46 & 0.04 \\
\hline Total autumn & 40.24 & 0.44 & 6.10 & 0.06 \\
\hline Total spring & 41.01 & 0.49 & 6.45 & 0.06 \\
\hline Total . . . . . . . & 40.68 & 0.47 & 6.30 & 0.06 \\
\hline
\end{tabular}

The number of females analyzed for each population is given in parentheses.

TABLE 2

Three way factorial ANOVA using the arc sine transformation

\begin{tabular}{|c|c|c|c|}
\hline Sources of variation & DF & MS & $F$ \\
\hline Eye colour & 2 & 0.064 & $24.316^{* *}$ \\
\hline Habitat $\ldots \ldots \ldots \ldots \ldots$ & 2 & 0.018 & $6.755^{*}$ \\
\hline$\ldots \ldots \ldots \ldots$ & 1 & 0.002 & 0.587 \\
\hline Eye colour-habitat $\ldots \ldots \ldots$ & 4 & 0.001 & 0.512 \\
\hline Eye colour-season $\ldots \ldots \ldots$ & 2 & 0.000 & 0.046 \\
\hline Habitat-season $\ldots \ldots \ldots \ldots$ & 2 & 0.001 & 0.286 \\
\hline Eye col.-hab.-season & 4 & 0.003 & \\
\hline Total & 17 & & \\
\hline
\end{tabular}

DF : Degrees of freedom.

MS : Observed mean square.

$\mathrm{F}$ : Value of $\mathbf{F}$ test.

${ }^{*}: P<0.05{ }^{* *}: P<0.01$.

Three different eye colour mutants (dark, light and caramel), 3 habitats (cellar, vineyard and pine-wood) and 2 seasons (spring and autumn) have been taken into account. 
those in which a higher number of individuals were analyzed. However, the population with the highest frequency was the cellar in spring in spite of being the population with the highest number of flies analyzed.

Considering each of the eye colour phenotypes $(D E, L E$ and $C E)$ separately, there were neither significant differences among the habitats nor between the seasons; therefore, the highest proportion of eye colour mutations observed in the cellar cannot be attributed to any specific type of mutation, but is the result of a significant increase in all types. On the other hand, in all the populations there was a greater number of dark eye colour mutants, which agrees with the complexity of the pteridines pathway and the simplicity of that of the ommochromes. By means of a three way ANOVA (table 2) considering the three different eye colours, the three habitats and the two seasons, significant differences among the eye colours in favour of the dark colour and among the habitats in favour of the cellar can be observed, while the interaction between these factors is not significant. The STUDENT-NEWMAN-KEULS multiple range test groups the light and caramel colours in one class and the dark colour in a separate class (with a higher mean). The number of eye colour mutations per fly are distributed randomly in the six populations, fitting a Poisson distribution in all cases ; nevertheless, there is a small lack of females without mutations, principally in the cellar collections.

Table 3 gives the number of mutations analyzed for each population, the distribution of the different kinds of alleles $(D E, L E$ or $C E)$ and the number of different mutations in each population. We have considered as dark eye, those mutants with a phenotype similar to $s e, s f, H n$, dke, etc. ; as light eye, those mutants with a phenotype similar to $c n, c d, s t, v$, etc. and as caramel eye those mutants with a phenotype similar to $p n, g, r s, r b$, etc. The distribution of alleles in all populations fit also a Poisson distribution; nevertheless, there was a tendency to find an excess of mutations represented only in one female.

TABle 3

Number of alleles for each mutation in each population

\begin{tabular}{|c|c|c|c|c|c|c|}
\hline Populations . & $\begin{array}{l}\text { Cellar } \\
\text { autumn }\end{array}$ & $\begin{array}{l}\text { Cellar } \\
\text { spring }\end{array}$ & $\begin{array}{l}\text { Vineyard } \\
\text { autumn }\end{array}$ & $\begin{array}{l}\text { Vineyard } \\
\text { spring }\end{array}$ & $\begin{array}{l}\text { Pine-wood } \\
\text { autumn }\end{array}$ & $\begin{array}{l}\text { Pine-wood } \\
\text { spring }\end{array}$ \\
\hline Analyzed mutations & 42 & 52 & 13 & 27 & 18 & 27 \\
\hline 1 occurrence ..... & $22(10,4,8)$ & $17(9,4,4)$ & $9(3,4,2)$ & $15(7,3,5)$ & $12(7,2,3)$ & $17(10,4,3)$ \\
\hline 2 occurrences & $5(3,2,0)$ & $6(1,3,2)$ & $2(2,0,0)$ & $2(2,0,0)$ & $1(0,1,0)$ & $3(1,2,0)$ \\
\hline 3 occurrences. & $1(1,0,0)$ & $3(2,0,1)$ & - & - & - & - \\
\hline 4 occurrences . . & - & $1(0,1,0)$ & - & - & $1(1,0,0)$ & $1(1,0,0)$ \\
\hline 7 occurrences & $1(1,0,0)$ & - & - & - & - & 一 \\
\hline 8 occurrences & - & - & - & $1(1,0,0)$ & 一 & 一 \\
\hline 10 occurrences & - & $1(1,0,0)$ & 一 & - & - & 一 \\
\hline $\begin{array}{l}\text { Number of different } \\
\text { mutations } \ldots \ldots \ldots\end{array}$ & $29(15,6,8)$ & $28(13,8,7)$ & $11(5,4,2)$ & $18(10,3,5)$ & $14(8,3,3)$ & $21(12,6,3)$ \\
\hline
\end{tabular}

The number in brackets indicates dark eyes $(D E)$, light eyes $(L E)$ and caramel eyes $(C E)$ respectively. The last line gives the different mutations in each population.

$1,2,3 \ldots$ occurences indicate that the mutations were found respectively in $1,2,3 \ldots$ females. 
As seen in table 4 , the populations showing the highest number of allelic crosses among them were CS (cellar spring), VS (vineyard spring) and PA (pine-wood autumn). These populations also showed the highest allelism within populations. On the contrary, CA (cellar autumn), VA (vineyard autumn) and PS (pine-wood spring) were the populations which showed the lowest allelic crosses and simultaneously the lowest allelism within populations. Both allelic crosses (within and between populations) have the same order of magnitude.

TABLE 4

Frequency of allelic crosses within each population and between populations

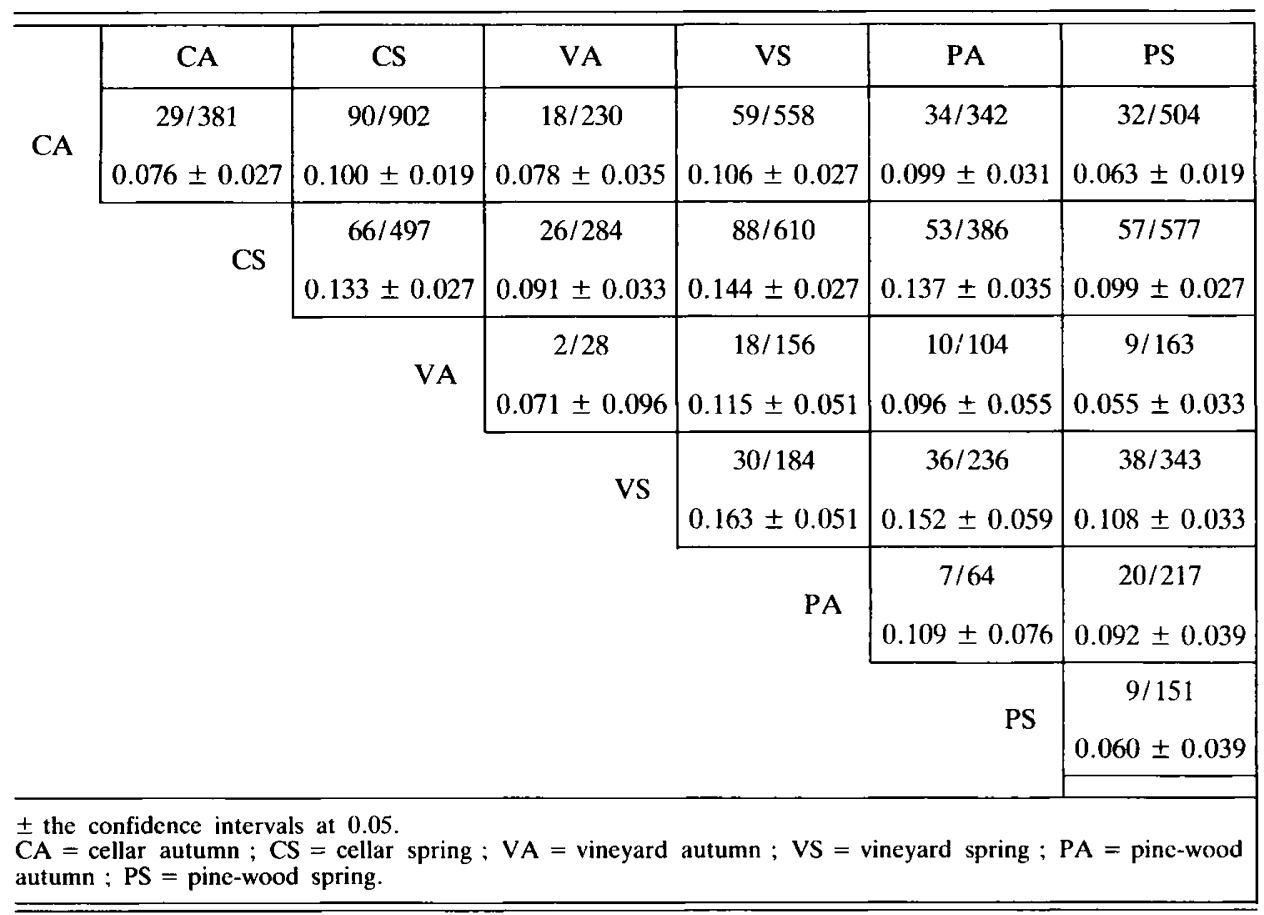

By means of a factorial analysis of correspondences and its three-dimensional representation of the points corresponding to the six populations (fig. 1) it can be observed that the populations which are nearest are the cellar ones, the vineyard and the pine-wood populations being at the same euclidian distance.

The effective sizes $\left(N_{e}\right)$ were estimated considering the variation in gene frequency between the autumn and spring collections (0.1869 in cellar, 0.1254 in vineyard and 0.1549 in pine-wood), the number of loci used (48 in cellar, 27 in vineyard and 34 in pine-wood) and the number of generations between the two collections (12 in cellar and vineyard and 7 in pine-wood). The effective sizes were high in all cases, cellar $12000 \pm 2448$; vineyard $15000 \pm 4151$; pine-wood $17500 \pm 4305 . N_{e}$ is slightly smaller in the cellar, which was predictable from the peculiar characteristics of this habitat (protected environment, confinement, isolation, etc.). 


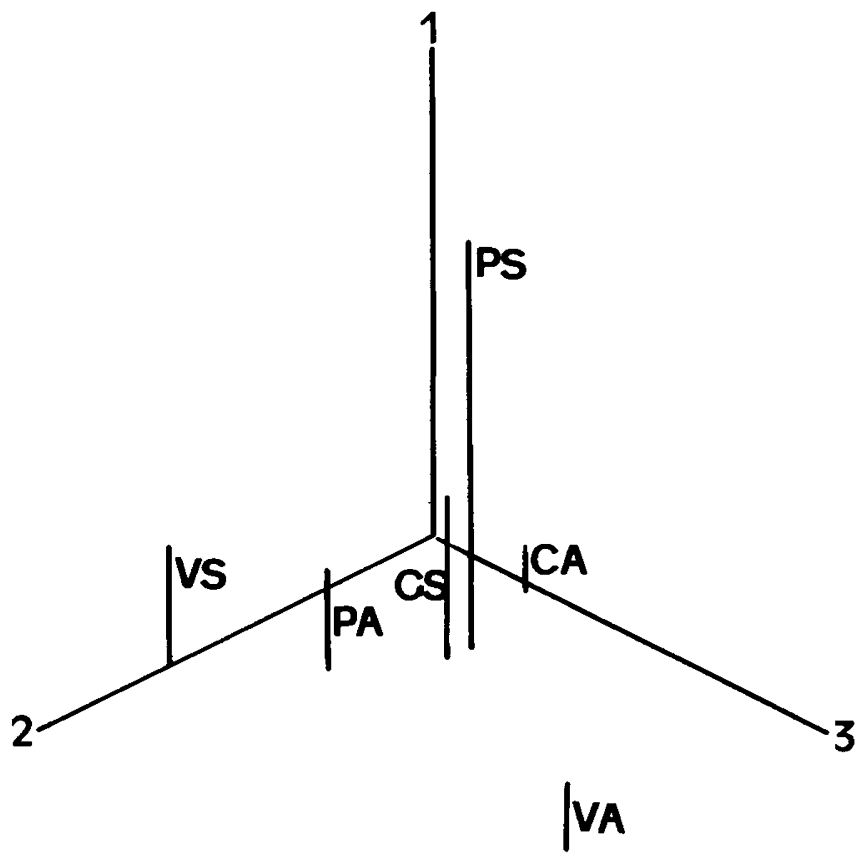

Fig. 1

Three-dimensional graph from the factorial analysis of correspondences. $C A=$ cellar autumn,$C S=$ cellar spring, $V A=$ vineyard autumn $V S=$ vineyard spring, $P A=$ pine-wood autumn, $P S=$ pine-wood spring.

\section{TABLE 5}

Number of different eye colour loci in each of the six populations analyzed (the percentages are based on the estimate of 112 different eye colour loci found in the literature). In the cellar, in the vineyard and in the pine-wood, considering the two captures in each case. In the autumn and in the spring, considering the three captures in each case. In total, considering the six captures

\begin{tabular}{l|c|c|c}
\hline \multirow{2}{*}{ Cellar $\ldots \ldots \ldots \ldots \ldots \ldots \ldots \ldots$} & $29(25.89 \%)$ & $28(25.00 \%)$ & $46(41.07 \%)$ \\
\cline { 2 - 4 } Vineyard $\ldots \ldots \ldots \ldots \ldots \ldots$ & $11(9.82 \%)$ & $18(16.07 \%)$ & $26(23.21 \%)$ \\
Pine-wood $\ldots \ldots \ldots \ldots \ldots \ldots$ & $14(12.50 \%)$ & $21(18.75 \%)$ & $33(29.46 \%)$ \\
\hline Total $\ldots \ldots \ldots \ldots \ldots \ldots$ & $43(38.39 \%)$ & $55(49.11 \%)$ & $87(77.68 \%)$ \\
\hline
\end{tabular}

The values of average heterozygosity were low, identical in both estimation methods and rather similar in all populations, the overall mean being about 0.11 . The pine-wood populations were the most different : in autumn the higher heterozygosity is recorded and in spring the lowest. 
The genetic distances obtained by means of five different indexes were small and similar in all cases, independently of the index used, being a little larger in autumn than is spring.

Assuming that the number of different loci reported presently for eye colour mutations is about 112 (LindSLEY \& GRELL, 1972, and for a complete review of the eye colour mutations, see Dros. Inf. Serv., 1985) the percentage of different heterozygous loci found in the populations analysed is reflected in table 5. This percentage was higher in cellar and in spring populations. Amongst the 87 different eye colour loci found, 46 were dark coloured eye, 20 light coloured eye and 21 caramel coloured eye.

\section{Discussion}

BcEsIGER (1953) has found $0.666(76 / 114)$ and $0.828(106 / 128)$ visible mutations per fly in two consecutive captures in a Swiss population and $0.820(259 / 316)$ in a Spanish population of D.melanogaster. The same author (1962) has estimated that there are about 4.2 mutant recessive genes per female maintained in a heterozygous state. This variability is higher than those obtained by us, but BoESIGER had studied all types of morphological mutations. ANXOLABÉHèRE et al. (1976), studying variability in a natural population of D.melanogaster (Mèze, France) during four consecutive years, have found that an individual was heterozygous only for $0.3 \%$ of its morphological loci. Some of the loci studied by these authors (garnet, rosy, ruby) were never polymorphic in that population while others (sepia, rouge, vermilion, vin) were polymorphic in all the captures. These small percentages of variability with regard to our results are logical because these authors have studied specific loci, not total variability. MENGUAL (1977), in a small cellar in Gerona (Spain), has detected ten eye colour mutants in eight different females out of twenty analyzed; this result agrees with the high proportion of heterozygous females found in the cellar captures of our study, significantly higher than in the vineyard and pine-wood populations which do not differ from each other.

The frequencies of each one of the mutations found in our populations are not within the range ordinarily defined as polymorphic, since the most frequent allele, present in all populations analyzed (safranin, sf $2: 71.5$ ) was found at frequencies of $0.0098-0.0313$, therefore the polymorphism at these loci is relative, because the frequency of the wild allele is always higher than 0.96 .

The allelism frequencies within populations varied between 6 and $16 \%$. There is no high number of allelic crosses in any one specified habitat or season of the year. Out of the few studies on visible mutations in natural populations, none included allelism tests. Nevertheless, there are many studies on allelism of lethal genes (IvES, 1945 ; Oshima \& Kitagawa, 1961 ; Watanabe, 1969 ; Mukai \& Yamaguchi, 1974). GonZÁlez \& MÉnsua (1987) have studied allelism of lethal third chromosomes, in the same population captured in cellar or in vineyard during the autumn. The rates obtained were $0.85 \%$ for CA and $0.64 \%$ for VA $(0.33$ being the allelism frequency between populations). These frequencies are very small with no significant differences among the three estimates at the $5 \%$ level.

From the factorial analysis of correspondences it can be seen that the closest populations are the cellar ones, the other habitats remaining at approximately the same 
euclidian distance. It seems also that autumn populations are more separate from each other than spring populations ; a cellar-vineyard-pine-wood cline according to geographical distance was not detected. There are clusters of mutations in the six populations studied.

The relation between population genetics and ecology culminates with the consideration of population size, which is affected by the genotype and by environmental factors. The populations analyzed have high effective sizes, the size in the cellar being slightly smaller. GonZÁlez \& MénSUA (1987), using lethal allelism from the same autumn capture of the cellar and vineyard populations found effective sizes of $N_{e}$ : $8000-11000$ and $N_{e}: 15000-18000$ respectively, similar to the values of the present paper. They consider the smaller size estimated in the cellar as essentially due to consanguinity, which was confirmed by the lethal allelism due to endogamy. Other studies of effective sizes working with lethals give very different sizes for geographically distant populations. The papers of Chol (1978) and KusaKabe \& MUKaI (1984a) give very low effective sizes for Korean and Japanese populations respectively, indicating the local isolation of these populations. In contrast, the American populations studied by Mukai \& Nagano (1983) have effective sizes higher than the populations from the present paper.

In a total of 381 analysed females, 87 different mutated eye colour loci have been identified, i.e. $79 \%$ of the previously described loci (about 112). On the contrary, a maximum of 24 mutated eye morphology loci (we do not know if these are different loci because the allelism tests have not been carried out) have been identified, which means approximately $18 \%$ of the previously described loci (about 133). This fact suggests either a high mutation rate for eye colour loci or an effect of natural selection acting on these loci.

The higher mutability of eye colour loci (Gassparian \& FADJAmI, 1974) explains the high percentage of heterozygous females found in all populations but it does not explain the significantly higher number of mutants in cellar populations. The differences in eye colour mutants between the cellar and vineyard populations (geographically very close) could be explained by a differential migration from the outside into the cellar resources (as found by McKenzIE \& PARsons, 1974), greatly accentuated in the vintage period since the available resources in the cellar are brought by man.

From the special conditions of the cellars (i.e. isolation and endogamy), a smaller frequency of heterozygotes than in the other populations would be expected. On the contrary we have found a higher number of heterozygous females for eye colour mutations. This means that the eye colour heterozygotes are maintained in this habitat. The conditions of the cellars (alcohol concentration, temperature, humidity, scarcity of light, confinement, etc.) could favour the accumulation of eye colour mutations in heterozygous state. Especially, it could be possible that the eye colour mutants are more resistant to alcohol (the principal nutritive resource in the cellars : McKenzIE \& Parsons, 1974 ; McKenzie, 1980 ; Monclus \& Prevosti, 1978-1979) or to acethaldehyde (toxic product coming from the ethanol metabolism in D. melanogaster). But it is necessary to specify that no relation is known between ethanol metabolism and the synthesis of eye pigments.

NáJERA (1985) has studied the competition between four eye colour mutants from cellar population and their wild alleles ; two different culture media were used, one supplemented with $10 \%$ ethanol and the other without ethanol. The five strains (wild and the four mutants) withstand a $10 \%$ ethanol concentration. An excess of heterozy- 
gotes was found in these populations. Considering that mutant strains had the same origin as the wild strain, the equilibrium frequency reached by the mutants may be attributed to the mutant loci themselves. NÁJERA \& MÉNSUA (1985b) studying viability of the same five strains at different ethanol concentrations (between 0 and $20 \%$ ) and at two levels of competition, have observed a high mean viability of the heterozygotes in all the experimental conditions tested. Moreover, the interaction competition versus alcohol concentration increases the viability of the mutant strains and still more that of the heterozygotes, but does not increase the viability of the wild strain.

The effective size of the cellar populations makes it improbable that genetic drift may influence the maintenance of the mutant alleles. The present work and the observations made by the authors in the previously cited papers, suggest that heterosis is the principal mechanism acting in favour of the maintenance of eye colour mutations in the cellar populations studied, although other mechanisms are not rejected.

Received October 24, 1986.

Accepted June 29, 1987.

\section{References}

Anxolabéhère D., Girard P., Palabost L., Périquet G., 1976. Stabilité des polymorphismes morphologique et enzymatique d'une population naturelle de Drosophila melanogaster. Arch. Zool. Exp. Gén., 117, 169-179.

Basiger E., 1953. Fréquence des mutations visibles dans deux populations naturelles de D.melanogaster. C.R. Acad. Sci. Paris, 236, 1999-2002.

BeEsiger E., 1962. Sur le degré d'hétérozygotie des populations naturelles de D.melanogaster et son maintien par la sélection sexuelle. Bull. Biol. Fr. Belg., 96, 3-122.

Cavalli-Sforza L.L., Edwards A.W.F., 1967. Phylogenetic analysis: models and estimation procedures. Evolution, 21, 550-570.

Сног Y., 1978. Genetic load and viability variation in Korean natural populations of Drosophila melanogaster. Theor. Appl. Genet., 53, 65-70.

Gassparian S., Fadjami S., 1974. Spontaneous mutations in D.melanogaster. Genetics, 77, s24.

González A., Ménsua J.L., 1987. Genetic polymorphism and high detrimental load in natural populations of Drosophila melanogaster from cellar and vineyard. Heredity (in press).

Hedrick D.A., Ginevan M.E., Ewing E.P., 1976. Genetic polymorphism in heterogeneous environments. Ann. Rev. Ecol. Syst., 7, 1-32.

Inoue Y., Tobari Y.N., Tsuno K., Watanabe T.K., 1984. Association of chromosome and enzyme polymorphism in natural and cage populations of Drosophila melanogaster. Genetics, 106, 267-277.

IVES P.T., 1945. The genetic structure of American populations of Drosophila melanogaster. Genetics, 30, 167-196.

Krimbas C.B., Tsakas S., 1971. The genetics of Dacus oleae. 5. Changes of esterase polymorphism in a natural population following insecticide control. Selection or drift ? Evolution, 25, 454-462.

Kusakabe S., Mukal T., 1984a. The genetic structure of natural populations of Drosophila melanogaster. 17. A population carrying genetic variability explicable by the classical hypothesis. Genetics, 108, 393-408.

Kusakabe S., MukaI T., 1984b. The genetic structure of natural populations of Drosophila melanogaster. 18. Clinal and uniform genetic variation over populations. Genetics, 108, 617632.

Legendre L., Legendre P., 1979. Ecologie numérique. Tome 2: La structure des données écologiques. 247 p., Masson et PUF, Paris. 
Lewontin R.C., HubBy J.L., 1966. A molecular approach to the study of genic heterozygosity in natural populations of $D$. pseudoobscura. Genetics, 54, 595-609.

LindSLEY D.L., Grell E.H., 1972. Genetic variations of Drosophila melanogaster. Carnegie Inst. Wash. Publ., $\mathrm{n}^{\circ} 627$.

McKenzie J.A., 1980. An ecological study of the ADH polymorphism of D.melanogaster. Aust. J. Zool., 28, 709-716.

McKenzie J.A., Parsons P.A., 1974. Microdifferentiation in a natural population of D.melanogaster to alcohol in the environment. Genetics, 77, 385-394.

Mengual V., 1977. High frequency of eye colour mutants in a natural population of D.melanogaster. Dros. Inf. Serv., 52, 69.

Monclús M., Prevosti A., 1978-1979. Cellars habitat and Drosophila populations. Genét. Ibér., 30-31, 189-202.

Mukal T., Nagano S., 1983. The genetic structure of natural populations of Drosophila melanogaster. 16. Excess of additive genetic variance of viability. Genetics, 105, 115-134.

Mukal T., Yamaguchi O., 1974. The genetic structure of natural populations of D.melanogaster. 11. Genetic variability in a local population. Genetics, 76, 339-366.

NÁJERA C., 1985. Variabilidad de mutaciones que afectan al color de los ojos en poblaciones naturales y experimentales de D.melanogaster. Tesis Doctoral, Universidad de Valencia.

NÁJERA C., MÉnsua J.L., 1985a. Study of eye colour mutant variability in natural populations of D.melanogaster. 1. Cellar. Dros. Inf. Serv., 61, 131.

Nájera C., Ménsua J.L., 1985b. Effect of alcohol and competition levels on viability of eye colour mutants of Drosophila melanogaster. Génét. Sél. Evol., 17, 331-340.

NeI M., 1972. Genetic distance between populations. Am. Nat., 106, 283-292.

NEI M., 1978. Estimation of average heterozygosity and genetic distance from a small number of individuals. Genetics, 89, 583-590.

Oshima C., Kitagawa O., 1961. The persistence of deleterious genes in natural populations of D.melanogaster. Proc. Jpn. Acad., 36, 158-162.

PollaK E., 1983. A new method for estimating the effective population size from allele frequency changes. Genetics, 104, 531-548.

Prevosti A., 1974. La distancia genética entre poblaciones. Miscellanea Alcobé, E, 109-118, Barcelona.

RoGerS J.S., 1972. Measures of genetic similarity and genetic distance. Stud. Genet., 7, 145-153, University of Texas.

SiNGH R.S., HickeY D.A., David J., 1982. Genetic differentiation between geographically distant populations of D.melanogaster. Genetics, 101, 235-256.

SoKal R.R., Rohlf F.J., 1981. Biometry. 859 p., Freeman, San Francisco.

Sokal R.R., Sneath P.H.A., 1963. Principles of numerical taxonomy. 359 p., Freeman, San Francisco.

SPenCER W.P., 1947. Mutations in wild populations in Drosophila. Adv. Genet., 1, 359-402.

Sturtevant A.H., 1919. A new species closely resembling D.melanogaster. Psyche, 26, 153-155.

Watanabe T.K., 1969. Frequency of deleterious chromosomes and allelism lethal genes in Japanese natural populations of D.melanogaster. Jpn. J. Genet., 44, 171-187. 